\title{
Escolaridade e inserção no mercado de trabalho de indivíduos nascidos com fissura labiopalatina
}

\author{
Educational level and job market inclusion in subjects \\ born with cleft lip and palate
}

\author{
Priscila Maria Trezza, ${ }^{1}$ Cristiane Faccio Gomes, ${ }^{2}$ Régio Márcio Toesca Gimenes, ${ }^{3}$ Ely Mitie Massuda ${ }^{4}$ \\ 'Associação de Apoio ao Fissurado Lábio-palatal de Maringá. Maringá, PR, Brasil. \\ 2ProLactare - Consultoria em Amamentação e Fonoaudiologia, Londrina, PR, Brasil. \\ 3Universidade Federal da Grande Dourados (UFGD), Dourados, MS, Brasil. \\ ${ }^{4}$ Centro Universitário de Maringá (UniCesumar). Maringá, PR, Brasil.
}

Recebido em: 07/07/2016 / Aceito em: 22/08/2016 / Publicado em: 18/10/2016

elymitie.m@gmail.com

\section{RESUMO}

A fissura labiopalatina é uma malformação congênita de elevada prevalência no Brasil e sua etiopatogenia é complexa. Seu tratamento necessita de abordagem interdisciplinar em razão das implicações físicas, psicológicas e sociais que comportam os problemas decorrentes. Os quadros com envolvimento do palato são os de mais difícil solução, de maior risco de sequelas estéticas e de comunicação, com risco de exclusão social, inclusive no trabalho. Objetivo: analisar a inserção de indivíduos nascidos com fissura labiopalatina no mercado de trabalho, sua trajetória escolar e nível de educação formal. Método: o presente trabalho é de caráter qualiquantitativo, do tipo exploratório e descritivo. A amostra foi composta dos prontuários clínicos de 98 indivíduos fissurados adultos (18 anos ou mais), de ambos os gêneros, acompanhados em associação especializada da cidade de Maringá, Estado do Paraná, Brasil. Resultados: os resultados indicam um nível de repetência superior à média nacional e ocupação em atividades e renda inferiores ao nível de competência de acordo com a formação escolar. Não foi encontrada correlação entre o nível de sequela e a escolaridade, o trabalho e a renda. Houve correlação entre o tipo de fissura e o nível de sequela. Considerações finais: a maioria dos fissurados estudados está colocada em empregos inferiores aos seus níveis de escolaridade.

Palavras-chave: Escolaridade; Emprego; Remuneração; Fissura Labial; Fissura Palatina.

\section{ABSTRACT}

Cleft lip and palate is a congenital malformation of high prevalence in Brazil and its etiopathogeny is complex. Its treatment demands interdisciplinary approach due to the physical, psychological and social factors that cause associated problems. Clinical conditions involving palate are the most difficult to solve, presenting higher risks of aesthetical and communication sequels, and also the risk of social exclusion, including at work. Objective: to analyze the inclusion of cleft lip and palate individuals in the job market, their academic trajectory and level of formal education. Method: this study is qualitative, quantitative, exploratory and descriptive. The sample consisted of clinical records of 98 adult (18 years or more) cleft individuals, both genders, followed up in a specialized association in the city of Maringá, Paraná State, Brazil. Results: results indicate an academic failing higher than the national average, and occupations with lower income and activities below their competence level when considering their educational background. No correlation was found between the sequel level and education, job and income. There was a correlation between the kind of cleft and the sequel level. Closing remarks: most of subjects born with cleft lip and palate is placed in jobs below their educational level.

Keywords: Educational Status; Employment; Remuneration; Cleft Palate; Cleft Lip. 


\section{INTRODUÇÃO}

A fissura labiopalatina (FLP) é uma das malformações congênitas mais comuns, com alta incidência no Brasil. Sua etiopatogenia é complexa, envolvendo fatores genéticos e ambientais e sua manifestação é variável em gravidade e extensão, podendo ser agrupada em três quadros principais: a fissura labial, a palatina e a labiopalatina. ${ }^{1,2}$

Os quadros com envolvimento do palato são os de mais difícil solução, implicam em longos tratamentos interdisciplinares e são os de maior risco de sequelas. Incluem-se nestas as cicatrizes, as alterações do crescimento da face, as maloclusões dentárias e os distúrbios de voz e fala. Além do aspecto estético, somam-se dificuldades de comunicação importantes, como ininteligibilidade de fala e voz hipernasal. Este conjunto de manifestações pode levar a dificuldades de socialização desde idade muito precoce, podendo acarretar problemas de escolarização, exclusão e baixa autoestima. ${ }^{3,4}$

Consequentemente, o indivíduo fissurado tem maior possibilidade de fracasso e abandono escolar, fato que pode gerar, na vida adulta, maior dificuldade de inserção no mercado de trabalho. Somam-se a este fator, as manifestações já citadas que podem permanecer como sequelas sem solução. O indivíduo fissurado que apresenta fala nasalizada e de difícil compreensão é alguém que pode ser julgado erroneamente como menos capaz e poderá ter menores chances de ser admitido em um emprego. Isto porque estas alterações de fala despertam no ouvinte a sensação de que o falante não tem inteligência normal. ${ }^{5}$

A legislação brasileira beneficia os indivíduos deficientes com cotas no mercado de trabalho. A FLP poderia ser categorizada como uma deficiência de natureza física, porém a lei julga que ela não incapacita o indivíduo para o trabalho.

Para se atingir os objetivos propostos foi realizada a descrição de dados referentes à escolaridade desta casuística, identificar o nível de escolaridade, desempenho, reprovas, abandono escolar, relatos de discriminação e preconceito e outros fatores negativos; identificar os setores, profissões de atuação e renda dos fissurados inseridos no mercado de trabalho; verificar a relação entre o nível de sequela e a escolaridade, a inserção no mercado de trabalho e a renda. O objetivo geral da pesquisa consistiu em verificar como os indivíduos fissurados adultos estão inseridos no mercado de trabalho e qual sua trajetória escolar e nível de instrução.

\section{MÉTODO}

A pesquisa caracteriza-se como um estudo quantitativo, do tipo exploratório e descritivo. A mesma foi realizada na AFIM - Associação de Apoio ao Fissurado Labiopalatal de Maringá, especializada no atendimento a pessoas com fissuras labiopalatinas e malformações craniofaciais, localizada no município de Maringá, Estado do Paraná, Brasil. A AFIM é uma associação, sem fins lucrativos, fundada em 1987, a partir da união de um grupo de pais e familiares de indivíduos fissurados da região. Atualmente, presta atendimento a cerca de 600 pacientes de Maringá e região, sem custo, de todas as classes sociais, e oferece os tratamentos complementares ao cirúrgico nas áreas de serviço social, fonoaudiologia, psicologia, pedagogia, nutrição, odontologia e ortodontia.

Indivíduos portadores de fissura labiopalatina, por hipótese, teriam dificuldades na inserção do mercado de trabalho devido às sequelas que lhe são peculiaridades.

A partir de levantamento da população de 192 pacientes fissurados, via banco de dados, com 18 anos ou mais, em acompanhamento na AFIM, foram selecionados 145 prontuários clínicos em razão do critério de exclusão (síndromes associadas, outras deficiências, alterações neurológicas). Destes, restaram 130, pois uma parte dos pacientes havia abandonado o tratamento e não podiam ser localizados.

Admitiu-se um erro máximo de $5 \%$ e utilizando um nível de confiança de $95 \%$, conforme recomendado na literatura. ${ }^{6-10} \mathrm{~A}$ amostra consistiu em 98 indivíduos que foram entrevistados individualmente e a entrevista incluiu perguntas sobre o passado escolar e o histórico profissional do sujeito e suas impressões pessoais sobre eles.

Para fins de análise posterior, o grau de sequela de cada sujeito foi classificado em leve, moderado ou severo conforme dados apresentados nos prontuários. Para essa classificação, foram analisados três indicadores: voz, fala e estética facial (presença de cicatrizes). A sequela foi considerada leve, moderada ou severa quando, respectivamente, apenas um dos indicadores, dois ou os três estavam alterados. Esta forma de classificar foi elaborada pelos pesquisadores, devido à inexistência de um instrumento pré-existente.

As entrevistas foram realizadas pessoalmente e via telefone. As entrevistas pessoais foram iniciadas com a explicação da pesquisa aos sujeitos, a assinatura do Termo de Consentimento Livre e Esclarecido (TCLE) em caso de concordância, e aplicação do questionário. Optou-se por realizar parte das entrevistas via telefone, pois muitos residiam em outros municípios. Nestes casos, o sujeito foi convidado a participar da pesquisa, sendo-Ihe lido o TCLE e, em caso de concordância, a entrevista foi realizada por este meio. O projeto foi aprovado sob parecer $n^{\circ} 112.870$, pelo Comitê de Ética em Pesquisa da UniCesumar - Centro Universitário de Maringá.

Os dados obtidos foram tabulados e analisados estatisticamente de forma descritiva utilizando-se testes não-paramétrico de Krushal-Wallis ${ }^{11}$ e de associação de Goodman ${ }^{12,13}$ para comparação entre médias e análise de correlação entre as variáveis analisadas. Para o teste de associação de Goodman, foram utilizadas letras latinas minúsculas para indicar as significâncias entre níveis de sequela, fixada a categoria de resposta e, maiúsculas, para comparação das respostas das categorias dentro do nível de sequela. Todas as comparações foram realizadas no nível de $5 \%$ de significância e a leitura das letras deve ser feita da seguinte maneira: i) Dois níveis de sequela acompanhados de uma mesma letra minúscula não diferem entre si $(p>0,05)$ quanto às frequências de ocorrências, fixada a classe de resposta; ii) Duas categorias de respostas acompanhadas de pelo menos uma mesma letra maiúscula não diferem entre si $(p>0,05)$ quanto às frequências de ocorrências, dentro do nível de sequela. 


\section{RESULTADOS E DISCUSSÃO}

A amostra é composta de 98 indivíduos, quanto ao gênero, tipo de fissura e faixa etária: quanto ao gênero: 46 do gênero feminino (46,9\%) e 52 do masculino $(53,1 \%)$; quanto à faixa etária: a faixa etária predominante foi a de 18 a 21 anos $(34,7 \%)$, seguida de 22 a 26 anos (32,7\%). O grupo de 27 a 31 anos representou $10,2 \%$ do total da amostra; de 32 a 36 anos, $11,2 \%$; de 37 a 41 anos, 4,1\%; e de 42 a 46 anos, $4,1 \%$; quanto ao tipo de fissura: a transforame $(56,7 \%)$ foi predominante, seguida da pós-forme $(21,4 \%)$ e pré-forame $(16,3 \%)$. $\mathrm{O}$ tipo mais prevalente de fissura encontrado segue ao identificado na literatura. ${ }^{14-19}$

$\mathrm{Na}$ Tabela 1 encontram-se as medidas descritivas da idade dos sujeitos e a análise de correlação entre idade e nível de sequela pelo teste não-paramétrico de Krushal-Wallis. ${ }^{11} \mathrm{O}$ limite inferior de idade foi 18 anos e o superior, 59 anos. Não houve correlação entre o nível de sequela e a idade do sujeito.

$\mathrm{Na}$ Tabela 2 verifica-se a distribuição dos casos pelo tipo de fissura em cada gênero. O tipo de fissura predominante foi a transforame, tanto nas mulheres (21 casos, $21,4 \%$ da amostra), quanto nos homens (38 casos, $38,8 \%$ da amostra). Apenas dois casos $(2,0 \%$ da amostra) apresentaram outro tipo de fissura, mediana e submucosa. Freitas et al. ${ }^{16}$ apontam a porcentagem de $1,9 \%$ de incidência de fissuras raras no Brasil, incluindo os dois tipos citados.

Na Tabela 3 realizou-se a distribuição do nível de sequela por tipo de fissura, e realizado teste de associação de Goodman. ${ }^{12,13}$ Observou-se diferença significante do nível de sequela de acordo com o tipo da fissura. Houve predominância da sequela leve na fissura pré-forame, da sequela moderada na transforame e mesma incidência de sequela leve e moderada na pós-forame. A sequela severa só ocorreu na transforame, com diferença significativa.

\section{Escolaridade e fissura labiopalatina}

A primeira pergunta da entrevista da presente pesquisa refere-se à escolaridade, ou seja, investiga se o sujeito havia estudado, continuava estudando ou nunca havia estudado e em que nível se encontrava, sendo assim distribuídos: 17 indivíduos (17,3\%) apresentaram o ensino fundamental; $52(53,1 \%)$ o ensino médio ou equivalente; $19(19,4 \%)$ o ensino superior; 8 $(8,1 \%)$ a pós-graduação; $2(2,04 \%)$ em outros (cursinho pré-vestibular e preparatório para concurso na polícia). Não houve nenhum sujeito sem estudo algum. Note-se que mais da metade possuem o ensino médio ou equivalente.

Estudo realizado no Centrinho - HRAC/USP com 65 pacientes fissurados adolescentes encontrou que $40 \%$ não haviam concluído o primeiro grau, e 14\% estavam em atraso no ensino formal. ${ }^{20}$

No presente estudo, dos 98 sujeitos, 30 (30,9\%) interromperam os estudos precocemente: 17 (17,3\%) sem completar o Ensino Fundamental e 13 (13,3\%) sem completar o Ensino Médio. As taxas de abandono escolar apontadas pelo IBGE ${ }^{21}$ para a região sul do Brasil, em 2010, alcançaram $0,3 \%$ nas séries iniciais do ensino fundamental, 2,8\% para as séries finais do ensino fundamental e $8,3 \%$ para o ensino médio. Portanto, o abandono escolar no grupo de fissurados foi superior à média geral da região.

Os motivos referidos pelos 30 sujeitos para o abandono dos estudos foram: a necessidade de trabaIhar $(51,5 \%)$; muitas reprovações $(12,1 \%)$; casamento $(9,1 \%)$; não gostava de estudar $(15,1 \%)$; morava no sítio $(6,1 \%)$ e outros $(6,1 \%)$. Alguns sujeitos mencionaram mais de um motivo. A situação socioeconômica da

Tabela 1 - Medidas descritivas da idade segundo o nível de sequela.

\begin{tabular}{|c|c|c|c|c|c|}
\hline \multirow[b]{3}{*}{ Nível de sequela } & \multicolumn{5}{|c|}{ Medida descritiva } \\
\hline & \multicolumn{2}{|c|}{ Valor } & \multicolumn{2}{|c|}{ Valor } & \multirow[b]{2}{*}{ Desvio padrão } \\
\hline & Mínimo & Mediana & Máximo & Média & \\
\hline Leve & 18,0 & 23,5 & 59,0 & 26,6 & 9,9 \\
\hline Moderado & 18,0 & 24,0 & 43,0 & 26,1 & 7,2 \\
\hline Severo & 18,0 & 24,0 & 53,0 & 25,9 & 8,3 \\
\hline
\end{tabular}

Tabela 2 - Distribuição dos tipos de fissura por gênero.

\begin{tabular}{lcccccccccc}
\hline & \multicolumn{1}{c}{ Tipo de fissura } \\
\cline { 2 - 9 } & \multicolumn{2}{c}{ Pré-forame } & \multicolumn{2}{c}{ Transforame } & \multicolumn{2}{c}{ Pós-forame } & \multicolumn{2}{c}{ Outro } \\
& $\mathbf{n}$ & $\%$ & $\mathbf{n}$ & $\%$ & $\mathbf{n}$ & $\%$ & $\mathbf{n}$ & $\%$ & $\mathbf{n}$ & $\%$ \\
\hline Gênero feminino & 8 & $8,2 \%$ & 21 & $21,4 \%$ & 15 & $15,3 \%$ & 2 & $2,0 \%$ & 46 & $46,9 \%$ \\
Gênero masculino & 8 & $8,2 \%$ & 38 & $38,8 \%$ & 6 & $6,1 \%$ & 0 & $0,0 \%$ & 52 & $53,1 \%$ \\
Total & 16 & $16,4 \%$ & 59 & $60,2 \%$ & 21 & $21,4 \%$ & 2 & $2,0 \%$ \\
\hline
\end{tabular}

Tabela 3 - Distribuição do tipo de fissura segundo o nível de sequela.

\begin{tabular}{|c|c|c|c|c|c|}
\hline \multirow[b]{2}{*}{ Nível de sequela } & \multicolumn{5}{|c|}{ Tipo de fissura } \\
\hline & Pré-forame & Transforame & Pós-forame & Outro & Total \\
\hline Leve & $16(40,00)$ b $B$ & $12(30,00)$ a $\mathrm{B}$ & $10(25,00)$ b B & $2(5,00)$ a $A$ & 40 \\
\hline Moderado & $O(0,00)$ a $A$ & $24(68,57)$ b C & $11(31,43)$ b $B$ & $O(0,00)$ a $A$ & 35 \\
\hline Severo & $0(0,00)$ a $A$ & $23(100,00)$ c B & $0(0,00)$ a $A$ & $O(0,00)$ a $A$ & 23 \\
\hline
\end{tabular}

Fonte: Elaborada pelos autores. 
família pode explicar a necessidade de os filhos começarem a trabalhar antes de concluírem os estudos, pela urgência de auxiliarem nas despesas da família, fato que pode ocorrer independentemente da fissura.

A Tabela 4 apresenta a distribuição do nível de escolaridade segundo o nível de sequela, com a análise pelo teste de associação de Goodman. ${ }^{12,13}$ Não foi encontrada correlação entre as variáveis.

A questão seguinte aborda as reprovações na escola, média das notas e sua opinião sobre a fissura como um fator de insucesso na escola. Assim, 43,9\% dos sujeitos afirmaram ter reprovado na escola, proporção superior ao apontado na população da região sul do país, onde se localiza a associação em estudo. Conforme o IBGE, ${ }^{21}$ as taxas de repetência na população geral, nessa região em 2005, foram de 9,9 \% nas séries iniciais do ensino fundamental, $14,9 \%$ para as séries finais do ensino fundamental e 14,3\% para o ensino médio.

Em relação às notas, prevaleceram as notas médias, entre 5 e 7, referidas por $53,1 \%$ dos sujeitos; $43,9 \%$ acima de 7 ; e $3 \%$ abaixo de 5 . Quanto à pergunta sobre o fato da FLP ter atrapalhado na escola mais da metade $(56,1 \%)$ respondeu que não.

A taxa de dificuldades de aprendizagem nas crianças com FLP é notoriamente aumentada, entre 30\% a $40 \%$, em comparação à taxa da população em geral, que é de $10 \%$ a $20 \%$. As dificuldades são complexas e de difícil compreensão, ${ }^{32}$ por envolverem muitos fatores, e que uma das áreas de maior alteração nas crianças com FLP é a da leitura e escrita. ${ }^{22,31}$ Este último dado contraria o declarado por outros autores,${ }^{23}$ que afirmam que a habilidade de leitura e escrita do fissurado é semelhante à das crianças sem fissura.

Questionados sobre o motivo pelo qual a fissura atrapalhou na escola, o principal motivo mencionado o preconceito por parte dos colegas $(67,8 \%)$, o que se manifestava por gozações, apelidos, provocações e até bullying. Um dos sujeitos recordou ter sido hostilizado pela própria professora, o que lhe foi motivo de angústia por todo o tempo em que permaneceu na escola.

Embora, à primeira vista, este fato não se relacione com a capacidade de aprendizagem, não é difícil avaliar o quanto é importante para uma criança ou adolescente serem aceitos por colegas e professores. A rejeição experienciada na fase de formação da personalidade pode resultar em uma autoimagem negativa, sentimentos de inadequação e inferioridade com todas as consequências conhecidas. Não é raro, na clínica, o relato de discriminação pelos próprios professores, que interpretam as dificuldades de fala como sinal de dificuldades cognitivas.

Os demais motivos quanto ao fato da FLP atrapalhar na escola, associam-se à necessidade de faltar muito na escola por causa do tratamento $(16,1 \%)$; dificuldade de fala $(11,3 \%)$; tinha dificuldades de ouvir por causa das otites $(3,2 \%)$; outros $(1,6 \%)$.

A criança que nasceu com fissura, mesmo que leve, sofre discriminação social. Experienciar a reação social de hostilidade à sua anomalia influi no seu desenvolvimento socioemocional. Embora a FLP não gere déficit intelectual, a experiência social negativa pode influenciar no desenvolvimento acadêmico. ${ }^{20} \mathrm{Em}$ estudo com adultos fissurados, apontam que provocações e gozações foram frequentes na vida dos indivíduos estudados e foram um preditor significativo de desajuste psicossocial na idade adulta. ${ }^{24}$

$\mathrm{Na}$ visão dos professores, o desempenho escolar dos alunos com fissura labiopalatina, sem anomalias associadas, está dentro da média da sala de aula. No entanto, aqueles que apresentam desempenho abaixo da média, caracterizam-se pela prevalência do gênero feminino, nível socioeconômico baixo superior, fissura labiopalatal, alterações no exame timpanométrico e problemas na inteligibilidade da fala. ${ }^{25}$

\section{Trabalho e fissura labiopalatina}

Na pergunta referente ao trabalho, dos 98 sujeitos, $73(74,5 \%)$ referiram estar trabalhando e $25(25,5 \%)$, não. Destes 25, sete nunca haviam trabalhado. Em estudo sobre a concepção de deficiência do indivíduo com FLP e suas dificuldades de inserção no mercado de trabalho, observou-se que $19,4 \%$ dos entrevistados afirmaram ter sofrido dificuldades de colocação em vagas de emprego devido à fissura. ${ }^{10}$

A taxa de desemprego no Brasil em julho de 2013 foi de 5,6\%. ${ }^{26}$ Portanto, a porcentagem de desemprego encontrada na amostra de fissurados foi bastante superior.

Analisando-se a distribuição do trabalho segundo o nível de sequela e aplicado o teste de associação de Goodman, ${ }^{12,13}$ verifica-se que não foi encontrada correlação significativa entre as variáveis (Tabela 5).

Tabela 4 - Distribuição do nível de escolaridade segundo o nível de sequela.

\begin{tabular}{|c|c|c|c|c|c|c|}
\hline \multirow[b]{2}{*}{ Nível de sequela } & \multicolumn{6}{|c|}{ Nível de escolaridade } \\
\hline & Fundamental & Médio & & Superior & Pós-graduação & Total \\
\hline Leve & $7(17,50)$ a $A$ & $19(47,50)$ & a $B$ & $11(27,50)$ a $A B$ & $3(7,50)$ a $A$ & 40 \\
\hline Moderado & $6(17,14)$ a $A$ & $20(57,14)$ & a $B$ & $6(17,14)$ a $A$ & $3(8,58)$ a $A$ & 35 \\
\hline Severo & $3(13,04)$ a $A$ & $13(56,52)$ & a $B$ & $5(21,74)$ a $A B$ & $2(8,70)$ a $A$ & 23 \\
\hline
\end{tabular}

Tabela 5 - Distribuição do trabalho segundo o nível de sequela.

\begin{tabular}{|c|c|c|c|}
\hline \multirow[b]{2}{*}{ Nível de sequela } & \multicolumn{3}{|c|}{ Trabalho } \\
\hline & Trtabalhando & Desempregado & \multirow{2}{*}{$\begin{array}{c}\text { Total } \\
40\end{array}$} \\
\hline Leve & $30(75,00)$ a $\mathrm{B}$ & $10(25,00)$ a $A$ & \\
\hline Moderado & $27(77,14)$ a $B$ & $08(22,86)$ a $A$ & 35 \\
\hline Severo & $16(69,57)$ a $A$ & $07(30,43)$ a $A$ & 23 \\
\hline
\end{tabular}

Fonte: Elaborada pelos autores. 
Quanto à ocupação dos indivíduos entrevistados, estas foram categorizadas conforme Classificação Brasileira de Ocupações (CBO). A CBO classifica cada grupo de ocupação de acordo com o nível de competência exigido para exercê-lo, estendendo-se do nível 1 a 4. O nível de competência "é função da complexidade, amplitude e responsabilidade das atividades desenvolvidas no emprego ou outro tipo de relação de trabalho". ${ }^{27}$

Dessa forma, o grupo e referidos níveis de competência segundo a CBO são decompostas por Grande Grupo (GG): GG0- Forças Armadas, policiais e bombeiros militares (não definido); GG1 - Membros superiores do poder público, dirigentes de organizações de interesse público e de empresas e gerentes (não definido); GG2 - Profissionais das ciências e das artes (4); GG3 - Técnicos de nível médio (3); GG4 - Trabalhadores de serviços administrativos (2); GG5 - Trabalhadores dos serviços, vendedores do comércio em lojas e mercados (2); GG6 - Trabalhadores agropecuários, florestais, da caça e pesca (2); GG7 -Trabalhadores da produção de bens e serviços industriais; GG8 - Trabalhadores da produção de bens e serviços industriais (2); GG9 - Trabalhadores de manutenção e reparação (2); o nível 1 é identificado como não qualificado. ${ }^{27}$

Conforme a CBO, ocupação dos indivíduos no período da entrevista, se concentram no GG5 $(31,6 \%)$, seguido do GG7 (20,5\%) e do GG3 (20,5\%). Os grupos exigem nível de competência 2, 2 e 3, respectivamente, o que significa pouca especialização e especialização de nível médio, respectivamente. Os grandes grupos que exigem nível de competência 2 entre os participantes da entrevista, somam $68,5 \%$. O GGO apresentou um indivíduo $(1,4 \%)$; GG2 (9,6\%); GG 4 (2,7\%); GG6 (8,2\%); GG9 $(5, \%)$.

Pode-se observar que a maioria dos fissurados estudados está colocada em empregos inferiores à sua formação escolar considerando que 52 indivíduos $(53,1 \%)$ possuem o ensino médio ou equivalente; 19 $(19,4 \%)$ o ensino superior; 8 a pós-graduação. No entanto, apenas sete indivíduos $(9,6 \%)$ estão colocados no nível de competência 4 e 15 no nível 3. A justificativa para tal fato pode estar relacionada a questões de ordem psicoemocional, como baixa autoestima. $\mathrm{Na}$ prática clínica, observa-se que existe uma tendência do indivíduo com FLP crescer com baixa expectativa quanto ao seu futuro, como se a fissura fosse impedimento para aspirar a uma qualidade de vida plena, com bom nível escolar e emprego com remuneração satisfatória.

Em pesquisa realizada com portadores de fissura labiopalatina, residentes em Bauru em 2006, de 18 a 35 anos e inseridos no mercado de trabalho, observou-se que a maioria dos sujeitos exercia funções que exigiam pouca ou nenhuma qualificação. ${ }^{28}$

Quanto à questão referente à idade em que os sujeitos da pesquisa começaram a trabalhar, observa-se que $64,3 \%$ dos sujeitos começaram a trabalhar antes de atingir 18 anos, e 13,3\%, antes dos 13 anos. Conforme discutido anteriormente, o fato de necessitar trabalhar precocemente indica a dificuldade financeira das famílias.

Nessas condições, a inserção no mercado de trabalho se deu em serviços de baixa remuneração. O trabalho mais referido foi o de lavrador, "na roça", muitas vezes na propriedade da família ou para auxiliar o trabalho dos pais $(13,2 \%)$. As demais atividades cita- das como primeiro trabalho foram: auxiliar de escritório $(9,9 \%)$; balconista/ atendente $(9,9 \%)$; auxiliar de produção (5,5\%); babá $(4,4 \%)$; auxiliar de pedreiro $(4,4 \%)$; auxiliar de marcenaria (3,3\%); caixa (3,3\%); auxiliar de lavanderia, costureira, garçom, cobrador, secretária, auxiliar de metalurgia; auxiliar de lava-jato, empacotador, professor, auxiliar de indústria $(2,2 \%$ para cada categoria); outros (20,8\%); não responderam $(3,3 \%)$.

Quanto à remuneração percebida pelos indivíduos entrevistados, em salários mínimos, observou-se a seguinte situação: cinco indivíduos $(5,1 \%)$ recebiam abaixo de um salário mínimo (SM); 45 (45,9\%) de um a dois SM; $15(15,3)$ de 2,1 a 2 SM; e sete $(7,1 \%)$ acima de três SM. Entre o entrevistados, 53,1\% possuem o ensino médio ou equivalente; $19,4 \%$ o ensino superior; $8,1 \%$ a pós-graduação, portanto, o nível de educação formal e remuneração percebida não encontram a devida proporção.

Também é relevante lembrar que Maringá se encontra entre as cidades brasileiras de maior IDHM (Índice de Desenvolvimento Humano Municipal), segunda colocada no estado do Paraná, ${ }^{29}$ o que faz supor que as oportunidades de emprego bem como o salário da região sejam superiores à média brasileira.

Conforme resultados de relatos de caso de tratamentos fonoaudilógicos realizados em hospital de Minas Gerais, os resultados apontaram para o fato de que as alterações de fala podem afetar a vida escolar, social e, sobretudo, a vida profissional, pois o mercado de trabalho coloca obstáculos para engajá-los para certos serviços. ${ }^{30}$

Sobre sustento pessoal e opinião sobre o trabalho e a fissura dos indivíduos, $61,2 \%$ recebe ajuda financeira de pais, cônjuge ou outro mostrando dependência de familiares ou cônjuges para o pagamento de despesas. Vale ressaltar que muitos sujeitos residem com os pais. Vive apenas do próprio salário 32,7\% dos entrevistados e $6,1 \%$ não respondeu.

Em relação à apreciação do sujeito em relação ao trabalho exercido e seu desejo de ter outra profissão, quando colocada a pergunta, $74,5 \%$ afirmou gostar do próprio trabalho, porém $56,1 \%$ afirmaram que desejariam ter outra profissão. As profissões apontadas como aquelas que desejariam exercer são profissões de maior rentabilidade e de maior grau de instrução. Dentre as mais frequentemente apontadas estão as de administrador, médico, engenheiro, advogado, veterinário, assistente social e farmacêutico.

Em estudo, a maioria dos participantes (70\%) afirmou estar satisfeito com o emprego, considerando bom relacionamento e respeito entre os funcionários e superiores (85\%), bom ambiente de trabalho (22\%) e identificação com o serviço que executa (14\%). Porém, ressaltam que os pacientes do Centrinho - HRAC/USP recebem intervenção do serviço social para colocação no mercado de trabalho, por meio de ação jurídica, na qual são considerados deficientes e, então, beneficiam-se da lei de cotas. ${ }^{28}$

Embora o Centrinho defenda a inclusão da FLP como deficiência, não há consenso dos profissionais, nem dos pacientes quanto a este ponto. Se, por um lado a inclusão facilitaria a colocação profissional nas vagas para deficientes, por outro, disfarça o fato da 
falta de atendimento adequado para todos os fissurados. A grande maioria das sequelas pode ser evitada com tratamento na época adequada e por profissionais especializados. Garantir o direito a cotas de deficiente é eximir o poder público da obrigação de oferecer este tratamento. As associações, como a AFIM, lutam com recursos próprios para suprir uma falha do sistema público de saúde em permitir o acesso universal e integral aos fissurados.

Para os 11 indivíduos que julgaram que a FLP prejudica seu trabalho em algo questionou-se qual seria este aspecto. $\mathrm{O}$ aspecto mais apontado $(63,5 \%)$ foi a dificuldade de fala, a qual prejudica a comunicação com colegas, clientes e superiores. Constatou-se que algumas dificuldades para inserção e permanência no mercado de trabalho dos fissurados labioplatina, ocorreram em razão de discriminação devido aos distúrbios de fala tais como hipernasalidade que prejudica a comunicação. ${ }^{28}$ Foram citadas também as faltas ocasionadas pelo tratamento, no relacionamento com colegas, vergonha pela aparência (cada um dos aspectos com 18,2\%) e na entrevista de emprego $(9,1 \%)$.

A Tabela 6 mostra a correlação entre o nível de sequela e a renda em salários mínimos (SM) do sujeito por meio do teste de associação de Goodman. ${ }^{12,13}$

Não foi encontrada correlação significativa entre as variáveis. Houve ocorrência ligeiramente maior da faixa salarial de 1 a 2 salários mínimos no nível de sequela moderado. Os resultados desta pesquisa são aparentemente contraditórios. Os indivíduos pesquisados parecem satisfeitos com sua situação profissional, mas ao mesmo tempo, não são remunerados de acordo com o nível de escolaridade e desejariam estar em empregos de maior nível. Referem que a FLP não foi empecilho na escola, mas admitem que sofreram preconceito e muitos desistiram antes de concluírem os estudos.

Pode-se hipotetizar várias justificativas para es tes resultados. Uma delas seria a de que o fissurado é visto com preconceito até por quem o trata, ou seja, espera-se que ele seja desajustado socialmente devido à malformação. Esta hipótese pode estar parcialmente correta, mas não justifica completamente os resultados contraditórios.

Outra explicação seria a de que o instrumento utilizado para a pesquisa não foi capaz de obter respostas mais aprofundadas da questão pelos fissurados. Falar de questões difíceis, que envolvem sofrimento psíquico, não é fácil. A entrevista foi realizada em um momento único. Talvez fosse necessário um procedimento que envolvesse um contato mais longo do pesquisador com o pesquisado para que ele admitisse suas dificuldades.
Negar o problema pode ser uma forma de defesa.

Finalmente, pensa-se na questão da expectativa de vida de um indivíduo que nasceu com uma diferença, passou por longos tratamentos invasivos, sofreu preconceitos e acaba por não esperar muito do próprio desempenho. Se a expectativa é baixa, um emprego está bom, mesmo que não seja aquele dos sonhos, refletindo certo conformismo com a própria vida.

Se um estudo semelhante for realizado daqui a dez anos, os resultados serão, provavelmente, diferentes. Isto porque o tratamento tem evoluído muito, tem se iniciado muito mais precocemente do que quando os sujeitos da presente pesquisa eram crianças e, portanto, certamente terão maior índice de sucesso na fala, na voz, na estética e no psiquismo.

\section{CONSIDERAÇÕES FINAIS}

Quanto à escolaridade dos indivíduos, predominou o nível médio. Quase a metade dos sujeitos referiu reprovas e houve abandono precoce dos estudos em cerca de um quinto da amostra. Os principais motivos relatados para o abandono escolar foram a necessidade de trabalhar e as reprovações. Foi frequente a referência de discriminação e preconceito sofridos durante o período escolar, cujo reflexo no desempenho acadêmico pode justificar as reprovações e o desencanto com os estudos. Por outro lado, um quarto dos sujeitos apresenta nível superior de ensino.

A maior parte dos sujeitos encontra-se empregado, em ocupações que exigem baixo nível de competência e com baixa remuneração. O relato de desejar ter outra profissão foi frequente e as profissões desejadas correspondem a níveis mais altos de competência e remuneração. Relaciona-se a colocação profissional encontrada com a baixa escolaridade e com a queixa de alguns indivíduos de que as dificuldades de fala consequentes da fissura prejudicam o desempenho e o relacionamento no trabalho.

Não foi encontrada correlação entre o nível de sequela e a escolaridade, o trabalho e a renda. Houve correlação entre o tipo de fissura e o nível de sequela, sendo a fissura transforame a única em que ocorreu o nível severo de sequela.

Um dos motivos pelo qual acabam por aceitar trabalhos inferiores à escolaridade ou carreiras que consideram mais atraentes pode ser associado à presença da fissura labiopalatina dos indivíduos portadores. Sugere-se considerar a questão da autoestima do portador da fissura em investigações futuras.

Tabela 6 - Distribuição da renda (SM) segundo o nível de sequela.

\begin{tabular}{|c|c|c|c|c|c|c|}
\hline \multirow[b]{2}{*}{ Nível de sequela } & \multicolumn{6}{|c|}{ Renda em salários mínimos } \\
\hline & Abaixo de 1 & 1 a 2 & 2,1 a 3 & Acima de 3 & Sem remun. & Total \\
\hline \multirow[t]{2}{*}{ Leve } & $4(10,00)$ & $16(40,00)$ & $6(15,00)$ & $3(7,50)$ & $11(27,50)$ & 40 \\
\hline & a $\mathrm{A}$ & a B & a $A B$ & a $\mathrm{A}$ & a $A B$ & \\
\hline \multirow[t]{2}{*}{ Moderado } & $0(0,00)$ & $20(57,14)$ & $5(14,29)$ & $2(5,71)$ & $8(22,86)$ & 35 \\
\hline & a $\mathrm{A}$ & a C & a B & a $A B$ & a BC & \\
\hline \multirow[t]{2}{*}{ Severo } & $1(4,35)$ & $09(39,13)$ & $4(17,39)$ & $2(8,70)$ & $7(30,43)$ & 23 \\
\hline & a $\mathrm{A}$ & a B & a $A B$ & a $A B$ & a $A B$ & \\
\hline
\end{tabular}




\section{REFERÊNCIAS}

1. Kuehn DP, Moller KT. Speech and language issues in cleft palate population: the state of art. Am Cleft Palate Craniofac J 2000;37:1-43.

2. Jesus MSV, Di Ninno COMS, organizadores. Fissura labiopalatina: fundamentos para a prática fonoaudiológica. São Paulo: Roca; 2003.

3. Tabith Junior AA. Distúrbios da comunicação em portadores de fissura labiopalatina: aspectos foniátricos. In: Melega JC, editor. Cirurgia plástica: fundamentos e arte - cirurgia reparadora de cabeça e pescoço. Rio de Janeiro: Medsi; 2002.

4. D'Agostinho L, Bautzer APD, Machado LP, Lima RA. Fissuras labiopalatinas e insuficiência velofarínea. In: Lopes Filho O, editor. Novo tratado de fonoaudiologia $3^{\mathrm{a}}$ Edição. São Paulo: Manole; 2013. p. 505-23.

5. Jesus MSV, Penido FA, Valente P. Avaliações fonoaudiológicas clínica e instrumental em indivíduos com fissura labiopalatina. In: Jesus MSV, Di Ninno COMS (Orgs.). Fissura labiopalatina: fundamentos para a prática fonoaudiológica. São Paulo: Roca; 2003. p.57-75.

6. Sartoris A. Estatística e introdução à econometria. São Paulo: Saraiva; 2003.

7. Callegari-Jacques SM. Bioestatística. Princípios e aplicações. Porto Alegre: Artmed; 2003.

8. Dowling D, Clark J. Estatística aplicada. $2^{a}$ Edição. São Paulo: Saraiva; 2006.

9. Bruni AL. Estatística aplicada à gestão empresarial. $2^{a}$ Edição. São Paulo: Atlas; 2008.

10. Arango HG. Bioestatística teórica e computacional: com banco de dados reais em disco. $3^{\text {a }}$ Edição. Rio de Janeiro: Guanabara Koogan; 2009.

11. Zar JH. Biostatistical analysis. $5^{\text {a }}$ Edição. New Jersey: Prentice Hall; 2009.

12. Goodman LA. On simultaneous confidence intervals for multinominal proportions. Technometrics 1965;7(2):247-54.

13. Goodman LA. Simultaneous confidence intervals for contrasts among multinominal populations. Annals of Mathematical Statistics 1964;35(2):716-25.

14. Graziosi MAOC, Salgado MAC, Castilho JCM. Investigação epidemiológica em indivíduos portadores de fendas labiais e/ou palatinas. Rev Fac Odontol São José dos Campos 2000;3(1):81-7.

15. Vasconcelos BCE, Silva EDO, Porto GG, Pimentel FC, Melo PHNB. Incidências de malformações congênitas labiopalatais. Rev Cir Traumat Buco-Maxilo-Facial 2002;2(2):41-6.

16. Freitas JAS, Dalben GS, Santamaria Júnior M, Freitas PZ. Current data on the characterization of oral clefts in Brazil. Braz Oral Res 2004;18(2):128-33. doi: 10.1590/S180683242004000200007

17. Baroneza JE, Faria MJSS, Kuasne H, Carneiro JLV, Oliveira JC. Dados epidemiológicos de portadores de fissuras labiopalatinas de uma instituição especializada de Londrina, Estado do Paraná. Acta Sci Health Sci 2005;27(1):31-5. doi: 10.4025/actascihealthsci.v27i1.1434.

18. Freitas e Silva DS, Mauro LDL, Oliveira LB, Ardenghi TM, Bönecker M. Estudo descritivo de fissuras lábio-palatinas relacionadas a fatores individuais, sistêmicos e sociais. RGO 2008;56(4):387-91.

19. Di Ninno COMS, Fonseca LFN, Pimenta MVE, Vieira ZG, Fonseca JA, Miranda ICC, Azevedo LL. Levantamento epidemiológico dos pacientes portadores de fissura de lábio e/ou palato de um centro especializado de Belo Horizonte. Rev CEFAC 2011;13(6):1002-08. doi:10.1590/S151618462011005000046

20. Graciano MIG, Tavano LD, Bachega MI. Aspectos psicossociais da reabilitação. In: Trindade IEK, Silva Filho OG, organizadores. Fissuras labiopalatinas: uma abordagem interdisciplinar. São Paulo: Santos; 2007. p. 311-333.

21. 21. IBGE. Censo Escolar. Séries históricas e estatísticas. [disponível na Internet]. 2015. [acessado em 2015 jul 15]. Disponível em: http://seriesestatisticas.ibge.gov.br/lista tema.aspx?op $=2 \&$ no $=9$

22. Richman L, McCoy TE, Conrad AL, Nopoulos PC. Neuropsychological, behavioral, and academic sequelae of cleft: early developmental, school age, and adolescent/young adult outcomes. Cleft Palate Craniof J 2012;49(4):387-396.

23. Tonocchi RC, Berberian AP, Massi G. Giselle. A escrita de sujeitos portadores de fissura lábio-palatina. Tuiuti: Ciência e Cultura 2008;39:41-62.

24. Hunt O, Burden D, Hepper P, Stevenson M, Johnston C. Self-reports of psychosocial functioning among children and young adults with cleft lip and palate. Cleft Palate Craniof $\mathrm{J}$ 2006;43(5):598-605.

25. Domingues $A B C$, Picolini MM, Lauris JRP, Maximino LP. Desempenho escolar de alunos com fissura labiopalatina no julgamento de seus professores. Rev Soc Bras Fonoaudiologia 2011;16(3):310-16. doi: 10.1590/S151680342011000300012 .

26. Ipeadata. Taxa e desemprego. [disponível na Internet] [acessado em 2015 jul 15]. Disponível em: http://www. ipeadata.gov.br/ExibeSerie. aspx?serid $=38401$

27. Brasil. Ministério do Trabalho e do Emprego. Classificação Brasileira de Ocupações. Disponível em http://www.mtecbo. gov.br/cbosite/pages/informacoesGerais.jsf;jsessionid $=0 \mathrm{jCY}$ MdMeMgZyVrn4qDUThJPw.slave18:mte-234-cbo-01

28. Santos LR, Graciano MIG, Valentim RCAAP. Trabalho e qualidade de vida de pessoas com fissura labiopalatina inseridas no mercado profissional em Bauru. Serviço Social \& Realidade 2007;16(2):83-121.

29. PNUD - Programa das Nações Unidas para o Desenvolvimento. Ranking IDHM Municípios 2010. Disponível em: http://www. pnud.org.br/atlas/ranking/ranking-idhm-municipios-2010.aspx

30. Lima MEF, Leal FB, Araújo SVS, Matos EF, Di Ninno COMS, Britto ATBO. Atendimento fonoaudiológico intensivo em pacientes operados de fissura labiopalatina: relato de casos. Rev Soc Bras Fonoaudiol 2007;12(3):240-46. doi: 10.1590/ S1516-80342007000300012.

31. Tabaquim, MLM, Vilela, LO, Benati, ER. Habilidades cognitivas prévias para aprendizagem de leitua e escrita de pré-escolares com fissura labiopalatina. Rev Psicopedag 2016;33(100):28-36.

32. Tabaquim M.L.M. Joaquim, R. M. Avaliação neuropsicológica de crianças com fissura labiopalatina. Arch Health Invest 2013;2(5):59-67.

Como citar: TREZZA, Priscila Maria et al. Escolaridade e inserção no mercado de trabalho de indivíduos nascidos com fissura labiopalatina. Cinergis, Santa Cruz do Sul, v. 17, n. 4, out. 2016. ISSN 2177-4005. Disponível em: <https://online.unisc.br/ seer/index.php/cinergis/article/view/7843>. Acesso em: 11 out. 2016. doi:http://dx.doi.org/10.17058/cinergis.v17i3.7843. 